\title{
Identificação de Aglomerações Produtivas no Nordeste: controvérsias sobre as políticas públicas para APLs
}

\author{
Laís Silva Santos \\ (Mestre pelo Curso de Mestrado em Economia Aplicada (CMEA/UFAL) \\ Thierry Molnar Prates \\ (Doutor em Desenvolvimento Econômico pela UFPR; Professor do CMEA/UFAL) \\ Adhemar Ranciaro Neto \\ (Doutor em Física pela UFAL; Professor do CMEA/UFAL)
}

\begin{abstract}
Resumo:
O trabalho tem por objetivo realizar uma análise crítica da classificação dos Sistemas Produtivos Locais (SPLs) existentes na Região Nordeste do Brasil no ano de 2013. Para que esse objetivo fosse alcançado utilizou-se dados da RAIS/MTE 2013 abrangendo 188 microrregiões da Região Nordeste. A partir desses dados, foram calculados os coeficientes locacionais (QL), e os coeficientes de gini locacionais (GL) por classe de indústria. Após, foram realizadas mais duas etapas, a primeira foi a aplicação do critério de nãoconformidade e a segunda foi o agrupamento das classes de atividades correlatas que encontram na mesma microrregião. O estudo conclui que nos estados de Sergipe, Paraíba, Rio Grande do Norte, Piauí e Alagoas a quantidade de aglomerados identificados pelo método científico é menor do que aqueles que fazem parte do Programa estadual de APLs. Já os estados do Ceará, Bahia e Pernambuco tem uma quantidade maior de aglomerados identificados do que os APLs apoiados pelo governo. O estado do Maranhão possui a mesma quantidade de aglomerados detectados e de APLs. Além disso, existe uma quantidade muito pequena de correspondência entre os aglomerados identificados pela pesquisa e aqueles apoiados pelos estados da região Nordeste. Isso se deve ao fato de que grande parte dos APLs do programa não tem grande relevância econômica em relação ao Nordeste em termos do número de empregos nesses setores e número de estabelecimentos.
\end{abstract}

Palavras-Chaves: Sistemas Produtivos Locais, Região Nordeste, Políticas Públicas

\begin{abstract}
:
The objective of this study is to perform a critical analysis of the classification of Local Productive Systems (SPLs) in the Northeast Region of Brazil in 2013. In order to achieve this objective, RAIS/MTE 2013 data were used covering 188 micro-regions of the Northeast. From these data, we calculated the locational coefficients (QL), and the locational Gini coefficients (GL) by each industry. After that, two more steps were taken; the first was the application of the nonconformity criterion and the second was grouping classes of related activities found in the same micro-region. The study concludes that in the states of Sergipe, Paraíba, Rio Grande do Norte, Piauí and Alagoas, the number of agglomerates identified by the scientific method is lower than those that are part of the State Program of APLs. On the other hand, the states of Ceará, Bahia and Pernambuco have a larger number of clusters identified than government-sponsored APLs. The state of Maranhão has the same amount of agglomerates detected and APLs. In addition, there is a very small amount of correspondence between the clusters identified by the survey and those supported by the states of the Northeast region. This is due to the fact that most of the program's APLs do not have great economic relevance in relation to the Northeast in terms of the number of jobs in these sectors and number of firms.
\end{abstract}

Key-Words: Local Productive Systems, Northeast Region, Public Policy. 


\section{1) INTRODUÇÃO}

O artigo explora a natureza dos APLs no Nordeste do Brasil, comparando aqueles que são apoiados com aqueles que são identificados. Tem como objetivo compreender a caracterização dos aglomerados produtivos de acordo com a literatura e as práticas correntes de identificação desses arranjos.

A hipótese levantada é que existe uma diferença significativa entre o que é possível identificar com dados oficiais e o que realmente existe, em se tratando de políticas públicas. Essa discrepância pode ser explicada por diversos motivos, o primeiro deles é a abundância de recursos públicos disponíveis para incentivo de APLs, que estimula a criação de política de sistemas (ou APLs). O segundo é a dificuldade de captação dessas atividades pela base de dados da Relação Anual de Informações Sociais (RAIS) do Ministério do Trabalho e Emprego, que subestima a magnitude das aglomerações, principalmente aquelas mais rudimentares, em função de que capta apenas o emprego formal, deixando de fora o trabalho informal que contém parte significativa do total do emprego, principalmente no Nordeste.

O terceiro motivo indica que a identificação de sistemas produtivos locais requer, não somente uma avaliação dos dados com utilização de filtros, mas uma observação minuciosa do local e da produção para evitar equívocos, como o de classificar uma grande empresa como um sistema, ou separar geograficamente uma cadeia de valor entre duas microrregiões.

O problema da identificação precária, muitas vezes delimitando APLs por critérios políticos ou outros interesses sociais, é a mistura de políticas públicas em situações diversas. Essa aplicação de políticas não diferenciadas, para situações extremamente díspares, conduz a grandes desperdícios de recursos públicos e ineficiência da política de incentivo a aglomerações industriais. Um misto de política industrial e social que gera resultados muitas vezes pífios em termos de promoção da localidade, empregos, renda e retorno do investimento governamental.

Pequenos aglomerados produtivos devem ser incentivados através de políticas próprias, voltadas para atender à necessidade local, evitando migrações e transferência da pobreza em grandes centros urbanos, criando oportunidades de renda e emprego para populações locais em territórios mais afastados, fomentando o desenvolvimento de cidades menores que ganham maior dinamismo. Cada política de promoção do desenvolvimento local deveria ser desenvolvida de baixo para cima, compreendendo as necessidades 
das populações locais e aplicando recursos de maneira pontual, primando pela eficiência tanto do resultado quanto do uso dos recursos.

\section{2) BREVE CARACTERIZAÇÃO DOS ARRANJOS PRODUTIVOS LOCAIS}

O debate sobre Sistemas e Arranjos no Brasil ganhou destaque na década de 2000. A Redesist (UFRJ) desenvolveu trabalhos importantes nesse sentido, reunindo um grande número de especialistas em diversas áreas relacionadas aos Arranjos Produtivos Locais (CASSIOLATO et al., 2000). Outros grupos de pesquisa importantes estão envolvidos com metodologias de identificação de APLs: o CEDEPLAR, com um foco sobre a economia regional (CROCCO et al., 2003), e a Unicamp, com enfoque maior sobre a Economia Industrial (SUZIGAN et al., 2003a; 2003b).

Em geral, a concentração espacial das firmas é um fator que demonstra ser eficiente na organização das mesmas e no estímulo à inovação. Este reconhecimento não é recente. As economias externas não planejadas foram apontadas por Marshall, em seu pioneiro trabalho sobre os distritos industriais ingleses no século XIX (MARSHALL, 1949). A análise seminal de Alfred Marshall sobre os distritos industriais ingleses inaugurou uma extensa literatura voltada à compreensão das aglomerações de pequenas firmas reunidas geograficamente. Marshall definiu as economias externas localizadas como aquelas derivadas dos transbordamentos (spillovers) de conhecimento, da presença de trabalho qualificado, e das interdependências e ligações (linkages) nos mercados locais. A proximidade entre as firmas pode proporcionar um ambiente de confiança, troca de informações e ação conjunta.

Atividades de inovação e ação conjunta em uma região específica são frequentemente estudadas utilizando-se da abordagem de clusters. Este formato de análise ganhou força nos últimos anos na literatura internacional, com inumeráveis exemplos de regiões de todo o mundo, que fizeram uso da eficiência coletiva ${ }^{1}$ e obtiveram sucesso nas inovações, exportações e mercados (SCHMITZ, 1999; SAXENIAN, 1994; NADVI; SCHMITZ, 1994; RABELLOTTI, 1999; COOKE; MORGAN, 1998; KNORRINGA, 1996, e muitos outros).

${ }^{1}$ A eficiência coletiva (collective efficiency) é a vantagem competitiva derivada de economias externas e ação conjunta (Schmitz, 1997). 
A economia industrial torna-se, desse modo, importante na explicação das externalidades, governança e do aparecimento da cooperação entre produtores e outros atores diretos e indiretos da cadeia produtiva. $\mathrm{O}$ ferramental de análise dos APLs (ou sistemas produtivos locais) é o mais apropriado para consolidar o entendimento de como as firmas se relacionam entre si e com os ativos institucionais que estão no seu entorno. A presença desses ativos como: universidades, centros de pesquisa, entidades de classe e treinamento, órgãos de fomento e de informação, é fundamental no desenho regional da inovação. Por outro lado, o isolamento das firmas torna muito complicado inovar com suas próprias forças.

São também centrais as instituições (descritas por North (1990) como as "regras do jogo" de uma sociedade), no entendimento das especificidades de uma região. As instituições são fundamentais no estabelecimento de rotinas e convenções, sobre as quais as firmas, famílias e governo atuarão. Muitas vezes, essas regras, que podem ser formais ou não, modificam o comportamento dos agentes para atender a determinada necessidade social. Assim, políticas que pretendam promover localidades através de aglomerados produtivos devem observar todas as características do entorno, inclusive as instituições nas quais a sociedade está inserida.

A abordagem de clusters concentra quatro principais linhas teóricas: a geografia econômica, economia de negócios, ciência regional e a literatura de inovação (SCHMITZ, 2003).

a) Geografia econômica: a corrente derivada do mainstream liderada por Krugman e seus colaboradores, que encontraram formas de modelar retornos crescentes do processo de ajuntamento das firmas (clustering) que levaram a uma nova teoria do crescimento, que reforçava a ideia de que a atividade de inovação atrai empresas para um cluster através dos transbordamentos do conhecimento (KRUGMAN, 1995; KRUGMAN; VENABLES, 1995).

b) Economia de negócios: Porter e seus colaboradores enfatizam a importância de aglomerações de empresas (clusters), dizendo que a vantagem competitiva na economia global deriva de fatores locais que mantém o dinamismo das firmas líderes (PORTER, 1990; 1998).

c) Ciência regional: A literatura de distritos industriais reflete o interesse de economistas da área regional por clusters (MARKUSEN, 1996). A ênfase na região como o centro de dependências não 
comercializáveis pode ser vista na abordagem do milieu innovateur (MAILLAT, 1996).

c) Inovação tecnológica: a inovação tem direcionado seu foco de análise para as regiões e localidades, entendendo que as características das regiões são as principais responsáveis pelo surgimento de inovações.

A variante dessa abordagem, utilizada de maneira recorrente nos estudos feitos no Brasil, é a abordagem de Arranjos Produtivos Locais (APLs), que denominam aglomerações produtivas, cujas articulações entre os agentes locais não é suficientemente desenvolvida (CASSIOLATO; LASTRES, 1999; SUZIGAN et al, 2003).

Essa corrida, por identificação desses aglomerados, se dividiu em duas linhas de estudo: aquela que derivava do ferramental de sistemas de inovação, sendo assim chamada de Sistemas Produtivos Locais e outra alternativa, que também deriva da abordagem de clusters, mas que se autodenominou de estudos de Arranjos Produtivos Locais, cujo ferramental teórico foi criado adequando às necessidades dos formuladores de políticas brasileiras, com uma amplitude muito maior, entendendo como um de seus objetivos, a manutenção de renda local e o desenvolvimento de pequenos negócios.

O ponto comum que pode ser verificado nessas experiências, que conforma uma de suas características essenciais, é a capacidade de geração de economias externas, que têm papel fundamental para o incremento da competitividade dos produtores locais.

Assim, o objetivo de identificar as aglomerações produtivas existentes no Nordeste brasileiro, utilizando critérios de ponderação pela participação no PIB e componentes principais é fundamental. As metodologias aqui apresentadas, discutidas e aplicadas permite a identificação estatística, a delimitação geográfica e a caracterização estrutural de APLs, por meio da utilização de indicadores de concentração setorial e especialização regional, combinados com variáveis de controle e filtros. Essa metodologia, aplicada aos dados da RAIS, tem-se revelado bastante útil em estudos já realizados em alguns estados, para orientar a formulação de diretrizes de políticas públicas e ações institucionais voltadas ao fomento das atividades produtivas e inovativas das empresas em APLs (ver, por exemplo, IPARDES, 2006).

Ressalte-se, entretanto, que neste trabalho será realizada a aplicação de apenas uma etapa da metodologia de mapeamento de APLs. A identificação e 
o mapeamento de APLs não pode prescindir de uma etapa subsequente de pesquisa de campo, com visitas e entrevistas às empresas e instituições locais, já que a utilização de ferramentas estatísticas e de bases de dados secundárias nem sempre permite confirmar a existência de um APL, nem verificar um elemento fundamental para a sua caracterização, que são as interações que ocorrem entre os agentes, empresas e instituições que fazem parte do arranjo sistema local de produção.

\section{3) POLÍTICAS PÚBLICAS E ABORDAGENS DE APLS}

A dificuldade de caracterização do fenômeno dos APLs, e os debates sobre o conceito mais adequado a ser utilizado, são bastante justificáveis, tendo em vista que essa denominação tem sido aplicada a uma grande diversidade de experiências em vários tipos de atividades. Além disso, em cada caso há características distintas em termos de sua história, evolução, organização institucional, contextos sociais e culturais em que se insere, com impactos importantes sobre a estrutura produtiva, a forma de organização da produção, os processos de aprendizado e a forma de governança local. Nesse sentido, é possível encontrar diferenças significativas entre muitas das diversas experiências de APLs no que se refere a graus de desenvolvimento, de integração da cadeia produtiva, de articulação e interação entre agentes e instituições locais, e de capacidades sistêmicas para a inovação.

A abordagem de APLs nos últimos 15 anos se tornou muito difundida entre gestores públicos das esferas estaduais e federais, assim como em entidades de apoio à indústria. Muitos programas foram implantados em todos os estados e a academia teve sua participação ao elaborar pesquisas (estudos) sobre a identificação e caracterização desses APLs. Devido ao sucesso do conceito e até da crença de que essa nova ferramenta seria a solução para todos os problemas, os governos criaram canais de financiamento e promoção de APLs por meio de políticas públicas horizontais e generosas.

Alguns exemplos dessas políticas são: a criação de grupos de trabalho permanente para APLs dentro do Ministério do Desenvolvimento, Indústria e Comércio (MDIC), o Banco do Nordeste do Brasil (BNB) e a Companhia de Desenvolvimento dos Vales do São Francisco e do Parnaíba (CODEVASF), Banco do Brasil, Banco Nacional do Desenvolvimento (BNDES). Outras fontes que podemos citar são: o Fundo de Combate e Erradicação da Pobreza (FECOEP), e no governo estadual, a Agência de Fomento de Alagoas 
(AFAL). Entidades não governamentais de apoio aos empresários como o SEBRAE/AL, ainda destinam para o Programa de Apoio aos Arranjos Produtivos Locais, o PAPL, uma quantidade de recursos importante, contemplando 88 municípios alagoanos.

\section{4) METODOLOGIA}

Utilizamos como base metodológica os estudos feitos pelo grupo da Unicamp (SUZIGAN et al., 2003; SUZIGAN et al., 2004; SUZIGAN, 2006),com algumas adaptações necessárias às especificidades locais. Fizemos um estudo sobre as microrregiões, mas com a abrangência maior, utilizando a região Nordeste como foco do estudo. Consideramos assim a região como se fosse um estado único, entendendo que as características das unidades da federação participantes são similares, no que tange à composição da estrutura produtiva, trabalho e setores de atividade, e que ainda o volume de produção dessa região em conjunto se assemelha aos estados mais desenvolvidos separadamente.

A Relação Anual de Informações Sociais (RAIS, 2013) do Ministério do trabalho, que fornece dados anuais sobre número de estabelecimentos, emprego por setor de atividade e localização geográfica das empresas formais, foi utilizada para calcular a concentração das atividades. Assim, podemos verificar quais atividades se concentram em todas as microrregiões da região Nordeste, desagregando essas informações até 4 dígitos da Classificação Nacional da Atividade Econômica (CNAE).

É importante fazer uma ressalva fundamental quanto às deficiências da RAIS, no que tange a sua abrangência. É conhecido de que no Brasil, e principalmente no Nordeste existe um enorme contingente de trabalhadores informais, isto é, cujas relações de trabalho não são firmadas através da assinatura da carteira de trabalho. A base de dados administrativos da RAIS não retrata esse trabalho não formalizado, podendo assim representar uma subestimação dos aglomerados produtivos, apesar do significativo aumento na formalização dos últimos anos.

A metodologia utilizada como base para a identificação e mapeamento dos aglomerados produtivos locais, aplica os índices de especialização produtiva e concentração regional. O Coeficiente Locacional (QL) é utilizado para determinar em quais regiões estão localizadas as atividades, e para determinar em quais localidades as atividades são mais concentradas utilizase o Gini Locacional (GL). Além desses dois indicadores, alguns filtros são 
colocados para somente identificar as aglomerações mais importantes e com maior peso nas microrregiões. O QL é calculado da seguinte maneira:

$$
Q L_{i j}=\frac{\frac{E_{i j}}{E_{i *}}}{\frac{E_{j}}{E_{*}}}
$$

Onde $E_{i j}=$ emprego do setor $\mathrm{i}$ na região $\mathrm{j}$;

$E_{i *=\sum_{j} E_{i j}}=$ emprego do setor i em todas as regiões;

$E_{J}=\sum_{i} E_{i j}=$ emprego em todos os setores da região j;

$E_{*=\sum_{i} \sum_{j} E_{i j}}=$ emprego de todos os setores em todas as regiões.

O QL mostra a especialização produtiva da região em determinada atividade, comparando-a com outras regiões da mesma área definida, que também estão envolvidas com essa atividade. Assim, foram selecionadas as microrregiões que possuem $\mathrm{QL}>1$ para determinar o número de combinações possíveis de classes industriais concentradas e microrregiões.

Nesses cálculos é importante discriminar qual a importância relativa daquela atividade específica no total dessa atividade na região. Utilizamos também o número de estabelecimentos como um filtro, para evitar o erro de declarar que uma localidade possui um sistema quando apenas uma empresa concentra todo o emprego daquela atividade. Assim, foram excluídas microrregiões em que menos de 10 estabelecimentos foram relacionados. Ademais, para selecionar apenas os casos mais relevantes economicamente para a região, outro parâmetro restritivo foi estabelecido, como em Suzigan et al (2006), de que a microrregião deveria alcançar pelo menos $1 \%$ de participação no emprego total do setor de atividade específico na região Nordeste.

Outro passo fundamental para identificar essas aglomerações produtivas é o Gini Locacional, como em Krugman (1991), Audretsch e Feldman (1996) e Suzigan et al (2006), e que nos revela o quanto aquela atividade é concentrada no território. O coeficiente varia entre zero e um, onde zero significa que as firmas são uniformemente distribuídas no território. Quanto mais próximo da unidade, mais concentrada geograficamente será a produção. Portanto, um Gini mais próximo de 1 indica uma maior 
probabilidade de que exista um sistema produtivo local. É possível então construir uma curva de Lorenz para cada um dos setores de atividades escolhidas mostrando como estão concentradas as atividades produtivas.

O filtro utilizado para determinar regiões mais concentradas foi o Gini maior do que 0,5 , rejeitando as microrregiões que apresentassem valores menores para esse índice de concentração (Tabela 1).

Tabela 1: Filtros e limites aplicados à região nordeste para a definição da tipologia de APL

\begin{tabular}{|c|c|c|c|c|}
\hline Região & $\begin{array}{c}\text { GINI } \\
\text { maior } \\
\text { que }\end{array}$ & $\begin{array}{c}\text { QL maior } \\
\text { que }\end{array}$ & $\begin{array}{c}\text { Número de } \\
\text { estabelecimentos } \\
\text { (maior ou igual a) }\end{array}$ & $\begin{array}{c}\text { Participação no } \\
\text { Emprego } \\
\text { (maior ou igual a) }\end{array}$ \\
\hline \multirow{4}{*}{ NE } & 0,5 & 1 & 10 & $1 \%$ \\
\hline & \multicolumn{2}{|c|}{ QL } & \multicolumn{2}{|c|}{ Participação no emprego } \\
\hline & $\begin{array}{c}\text { Limite } \\
\text { inferior }\end{array}$ & Limite & Limite inferior & Limite \\
\hline & 1 & 5 & $1 \%$ & $10 \%$ \\
\hline
\end{tabular}

Fonte: Suzigan (2006) - Elaboração própria.

\section{1) Aplicação da Metodologia aos Estados do NE}

A Região Nordeste possui desigualdades internas significativas, assim como o Brasil e suas diferentes regiões. Algumas localidades são prósperas e estão alinhadas com serviços e produção modernos de outros centros em regiões mais desenvolvidas do país, enquanto outras são extremamente atrasadas, carecendo de assistência governamental para não deixarem de existir. Na dianteira econômica estão as grandes capitais regionais como Salvador, Recife e Fortaleza. Essas capitais e suas regiões metropolitanas concentram as atividades produtivas mais importantes do Nordeste e também a maior parte dos empregos industriais da região.

Outras capitais, e suas respectivas regiões metropolitanas de magnitude secundária, possuem algumas atividades importantes, todavia não tão articuladas em termos de cadeias produtivas, baseadas em vantagens comparativas regionais, sejam elas ligadas a mão de obra barata ou recursos naturais específicos, mas ainda estão longe de alcançar as capitais mais adiantadas. O que dizer então do interior dos estados em questão? Se observarmos algumas cidades médias que ganharam mais projeção nos últimos anos devido aos programas de transferência e alguma atividade 
industrial, como Caruaru, Petrolina, Feira de Santana, Arapiraca, Campina Grande, Juazeiro do Norte, Mossoró, Imperatriz, etc., temos um cenário de expansão para o interior, enquanto o setor Agropecuário, mistura a alta produtividade da soja e cana-de-açúcar com setores de baixa, como laticínios, pequenas lavouras e criação de animais.

O panorama do emprego formal na região Nordeste se apresenta como na Tabela 2, colocando os três estados com economias mais fortes em primeiro lugar, como já se esperava, e o estado com maior número de empregos sobrepujando o que possui menor em oito vezes. Outro fato que devemos considerar é que sempre existe uma concentração muito grande de empregos formais nas cinco maiores microrregiões, corroborando a afirmativa de que o emprego informal tem um peso muito importante, principalmente nas regiões mais atrasadas. O caso de Alagoas é marcante, chegando a concentrar $91 \%$ do emprego nessas microrregiões. O Ministério do Trabalho estima que a informalidade no estado de Alagoas seja de aproximadamente 43,3\%, segundo dados do censo de 2010 .

Tabela 2: Número de Empregos e Microrregiões por Estados do Nordeste - Brasil, 2013

\begin{tabular}{cccccccc}
\hline UF & Rank. & $\begin{array}{c}\text { Número } \\
\text { Total de } \\
\text { Empregos }\end{array}$ & $\begin{array}{c}\text { Número } \\
\text { de } \\
\text { Micros }\end{array}$ & $\begin{array}{c}\text { Número de } \\
\text { Empregos } \\
\text { na Maior } \\
\text { Micro }\end{array}$ & $\begin{array}{c}\text { \%odo } \\
\text { Emprego } \\
\text { Total da } \\
\text { Maior } \\
\text { Micro }\end{array}$ & $\begin{array}{c}\text { Total de } \\
\text { Emprego } \\
\text { nas 5 } \\
\text { Maiores } \\
\text { Micro }\end{array}$ & $\begin{array}{c}\text { \%o do } \\
\text { Total } \\
\text { das 5 } \\
\text { Maiores } \\
\text { Micro }\end{array}$ \\
\hline BA & 1 & 403.708 & 32 & 137.399 & $35 \%$ & 263.947 & $67 \%$ \\
PE & 2 & 336.374 & 19 & 114.676 & $34 \%$ & 243.868 & $72 \%$ \\
CE & 3 & 327.911 & 33 & 191.687 & $58 \%$ & 273.665 & $83 \%$ \\
AL & 5 & 119.744 & 13 & 43.741 & $37 \%$ & 108.938 & $91 \%$ \\
PB & 4 & 108.149 & 23 & 50.030 & $46 \%$ & 92.565 & $86 \%$ \\
RN & 6 & 104.577 & 19 & 47.850 & $46 \%$ & 88.174 & $84 \%$ \\
MA & 7 & 80.308 & 21 & 25.955 & $32 \%$ & 56.342 & $70 \%$ \\
SE & 8 & 70.216 & 13 & 28.418 & $40 \%$ & 49.032 & $70 \%$ \\
PI & 9 & 48.149 & 15 & 29.848 & $62 \%$ & 40.419 & $84 \%$ \\
\hline
\end{tabular}

Fonte: Elaborado pelos autores. 
A maior microrregião de cada estado, isto é, aquela onde está localizada a capital em todos os casos, sempre concentra ao menos um terço de todo o emprego, no caso do Ceará, quase $60 \%$. Isso indica que a discrepância econômica entre as regiões dentro do estado é muito acentuada, enquanto estados como a Bahia e Pernambuco distribuem mais a produção entre as microrregiões desses estados. Isso não quer dizer que tenham indicadores de distribuição de renda ou outro indicador social mais favorável, apenas podemos dizer que outras microrregiões (ou cidades) polarizam atividades econômicas importantes, dividindo a participação do emprego estadual.

Com relação aos dados de estabelecimentos, a análise se repete. Concentração também nas microrregiões maiores, mas podemos observar no caso de Alagoas, que nos interessa neste estudo, que a porcentagem dos estabelecimentos nas 5 maiores microrregiões supera os outros estados, alcançando $86 \%$ desses estabelecimentos (Tabela 3). Isso pode indicar, além da concentração já observada, a existência de grandes empresas que concentram grande número de empregados, por exemplo, usinas de açúcar e álcool e a empresa Braskem.

Tabela 3: Empregos e Estabelecimentos por Unidade da Federação - NE

\begin{tabular}{ccccccc}
\hline UF & $\begin{array}{c}\text { Total de } \\
\text { empregos }\end{array}$ & $\begin{array}{c}\text { Total de } \\
\text { estab. }\end{array}$ & $\begin{array}{c}\text { Total } \\
\text { Estab. na } \\
\text { maior } \\
\text { micro }\end{array}$ & $\begin{array}{c}\text { \% de } \\
\text { estab. total } \\
\text { da maior } \\
\text { micro }\end{array}$ & $\begin{array}{c}\text { Total } \\
\text { estab. 5 } \\
\text { maiores } \\
\text { micro }\end{array}$ & $\begin{array}{c}\text { \% do } \\
\text { estab. } \\
\text { total das } \\
\text { 5 maiores } \\
\text { micro }\end{array}$ \\
\hline BA & 403.708 & 38.681 & 8.355 & 21,6 & 23.073 & 60 \\
PE & 336.374 & 20.270 & 7.996 & 39,4 & 15.096 & 74 \\
CE & 327.911 & 17.231 & 11.235 & 65,2 & 14.104 & 82 \\
AL & 119.744 & 5.185 & 2.696 & 52,0 & 4.474 & 86 \\
PB & 108.149 & 6.490 & 2.551 & 39,3 & 4.726 & 73 \\
RN & 104.577 & 7.733 & 3.377 & 43,6 & 6.005 & 78 \\
MA & 80.308 & 6.848 & 1.953 & 28,5 & 5.017 & 73 \\
SE & 70.216 & 5.790 & 2.397 & 41,4 & 4.279 & 74
\end{tabular}




$\begin{array}{lrrrrrr}\text { PI } & 48.149 & 4.721 & 2.420 & 51,2 & 3.729 & 79 \\ \text { NE } & 1.599 .136 & 112.949 & 11.235 & \text { NA } & 80.503 & \text { NA }\end{array}$

Fonte: Elaborado com base nos dados do Ministério do Trabalho e Emprego, 2013 (valores arredondados)

Quando aplicamos a metodologia de identificação de APLs para o Nordeste, tratamos como se fosse uma região monolítica, estabelecendo a relação entre o peso da produção local (microrregião) como uma fração da produção do NE. Isso nos permite aplicar mais rigorosamente a ferramenta de caracterização, sem cometer superestimações dos aglomerados para economias muito pequenas, como é o caso de Alagoas.

Para o Nordeste foram identificados 216 APLs que possuíam Coeficiente Locacional entre 1 e 5, e participação de $1 \%$ a $10 \%$ no emprego total desse setor no total da região Nordeste em 2013 (Tabela 4). Ainda com QL entre 1 e 5, foram identificadas 80 aglomerações que possuíam participação maior que $10 \%$ no total do emprego para cada setor específico. Daquelas aglomerações, cujo QL foi maior do que cinco, 79 tinham participação entre $1 \%$ a $10 \%$ e 42 participavam com mais de $10 \%$ total do emprego para cada setor.

Tabela 4: Número de APLs de Acordo com a Tipologia na Região Nordeste 2013

\begin{tabular}{|c|c|c|c|c|}
\hline Filtro & $\begin{array}{c}1<\mathrm{QL}<5, \\
1 \%<\mathrm{PE}<10 \%\end{array}$ & $\begin{array}{l}1<Q \mathrm{Q}<5, \\
\mathrm{PE}>10 \%\end{array}$ & $\begin{array}{c}\mathrm{QL}>5, \\
1 \%<\mathrm{PE}<10 \%\end{array}$ & $\begin{array}{c}Q L>5 \mathrm{e} \\
\mathrm{PE}>10 \%\end{array}$ \\
\hline $\begin{array}{c}\text { Número de } \\
\text { Aglomerações }\end{array}$ & 216 & 80 & 79 & 42 \\
\hline
\end{tabular}

Fonte: Elaboração própria.

O estudo dessas aglomerações e a comparação entre os programas de cada estado estarão presentes em trabalhos futuros, assim como o aprofundamento da análise do estado de Alagoas, observando cada APL identificado, ou não, pelo instrumento matemático, a fim de fazer inferências concretas sobre a caracterização de cada um deles. 


\section{5) RESULTADOS E COMPARAÇÕES PARA O ESTADO DE ALAGOAS}

Os programas de apoio a aglomerados produtivos têm se reproduzido por todo o território nacional. Utilizado como mecanismo alternativo de política industrial, o ferramental de APLs, por ter formato genérico e abrangente, é capaz de conter um número grande de formatos de aglomerados produtivos, desde sistemas produtivos integrados e inovadores a pequenos grupos de produtores desprovidos de tecnologia e escala. Tratam-se, neste último, de caso de arranjos que, mais do que projeção econômica, exportações e inovações de fronteira, buscam levar desenvolvimento econômico às localidades através de ações pontuais que implicam em aumento da produtividade e da qualidade de vida no local.

São 18 os APLs atendidos pelo programa governamental PAPL em Alagoas, a saber: APL Fruticultura do Agreste; APL Turismo Costa dos Corais; APL Turismo Lagoas e Mares do Sul; APL Turismo Caminhos do São Francisco; APL Móveis do Agreste; APL Móveis Maceió; APL Oleiro Cerâmico; APL Extração Artesanal de Granito; APL Tecnologia da Informação; APL Fitoterápicos; APL Horticultura do Agreste; APL Fruticultura do Vale do Mundaú; APL Mandioca do Agreste de Alagoas; APL Mel do Sertão Alagoano; APL Ovinocaprinocultura; APL Piscicultura Delta do São Francisco; APL da Apicultura Litoral e lagoas (Própolis Vermelha); APL da Rizicultura (LUSTOSA et al., 2014).

As ações de apoio são de fundamental importância em um dos estados menos desenvolvidos do Brasil, Alagoas, que possui regiões ainda muito atrasadas em que a renda ainda é muito baixa e o emprego precário e muitas vezes informal. Alguns desses APLs ainda são promessas, englobando atividades agropecuárias e que agregam menor valor, enquanto outros, como o de Móveis e de Tecnologias de Informação, ambos em Maceió, apresentam alguns resultados melhores, mas é difícil captá-lo pelos dados, por conta da enorme informalidade. O APL de Tecnologia da Informação em Maceió conta com 111 empresas, sendo que $91 \%$ delas são microempresas, no entanto, as manufaturas são minoria. $\mathrm{O}$ arranjo ainda é muito incipiente em termos de organização e cooperação. Já o APL de móveis em Maceió, conta com 333 empresas, que geram 949 postos de trabalho segundo, a Federação das Indústrias. Outros APLs que começam a aparecer como promessas são os de Fruticultura, Ovinocaprinocultura e Horticultura (LUSTOSA et al., 2014). 
Algumas (poucas) aglomerações têm correspondência com aos dados de emprego formal fornecido pela RAIS em 2013, mas a maior parte dos aglomerados só tem importância quando se relativiza o conceito, ou quando se observa apenas os aspectos sociais desses aglomerados para incluí-los em programas relacionados à APLs.

As ações dos agentes institucionais que apoiam esses APLs, via de regra, são pautadas pela capacitação para o trabalho, aumento da competitividade, marketing, educação ambiental, intermediação na cooperação entre os agentes, financiamento produtivo, busca de novos mercados, realização de feiras e tudo o que compõe o ambiente de negócios desses produtores de cada APL. Enfim, na organização da produção rudimentar para uma produção de mercado.

Assim, podemos destacar que, em Alagoas, as ações ligadas aos APLs têm, na maioria dos casos, um aspecto muito mais voltado para o lado social de geração de renda local ou aprimoramento dos métodos rudimentares de produção do que a pretensão de transformar o estado numa economia pujante ou exportadora de produtos com alto valor agregado e tecnologia de fronteira. Essas políticas auxiliam regiões e populações a aumentarem o rendimento do trabalho, elevam a produtividade e, consequentemente, a renda familiar, evitando migrações para as grandes cidades ou outras regiões, movimentando a economia local para que possa a partir desse desenvolvimento almejar passos mais largos.

As aglomerações encontradas encontram-se relacionadas na Tabela 5, em 11 grupos de setores de atividade. Aqui cabe salientar que alguns setores não obedecem aos critérios de conformidade, como descrito em Suzigan (2006), isto é, não possuem as características básicas para que possam ser chamados de APLs. Entre essas características estão: o tipo de atividade, a forma de organização da produção, a presença de empresas dominantes que detém ativos estratégicos e controlam suas próprias empresas coligadas, etc., e que, portanto, não se justifica como objeto de políticas para APLs. Segundo esse critério, o item fabricação e refino do açúcar, no caso de Alagoas foi descartado, por várias dessas características.

Novamente apontamos que nossa análise neste momento é apenas exploratória, e que para ser possível classificar um aglomerado como APL seria necessário uma pesquisa de campo mais detalhada. No entanto, algumas inferências mais simples podem ser feitas a partir dos dados encontrados. A despeito de conhecermos que o primeiro grupo, Produção de Lavouras Temporárias, se refere ao plantio da cana-de-açúcar, mantivemos este grupo, 
pois pode conter outras culturas passíveis de estudo mais aprofundado. As aglomerações identificadas na Pecuária referem-se principalmente à de leite em Arapiraca, e de corte em Serrana dos Quilombos. Nessa última, vemos a mudança produtiva com o surgimento da criação de gado em terreno acidentado, onde a cana-de-açúcar antes ocupava o espaço e agora com a crise deixou de ser plantada. Em Palmeira dos índios, a atividade correlata de Laticínios tem algumas empresas importantes como a Vale Dourado.

Tabela 5: APL's Identificados de Alagoas

\begin{tabular}{|c|c|c|c|c|c|c|c|}
\hline Grupo & Micro & GINI & QL & $\begin{array}{c}\text { Emp. } \\
\text { Classe }\end{array}$ & $\begin{array}{l}\text { Emp. } \\
\text { Total }\end{array}$ & $\begin{array}{c}\text { Emp. } \\
\text { Setor/Micro }\end{array}$ & Estab. \\
\hline $\begin{array}{l}\text { Produção de } \\
\text { Lavouras } \\
\text { Temporárias }\end{array}$ & $\begin{array}{c}\text { Mata } \\
\text { Alagoana }\end{array}$ & 0,79 & 1,74 & $2,22 \%$ & $1,27 \%$ & 1.789 & 212 \\
\hline Pecuária & $\begin{array}{c}\text { Serrana } \\
\text { dos } \\
\text { Quilombos }\end{array}$ & 0,60 & 3,23 & $1,51 \%$ & $0,47 \%$ & 943 & 124 \\
\hline $\begin{array}{c}\text { Pecuária } \\
\text { a }\end{array}$ & Arapiraca & 0,60 & 2,89 & $1,34 \%$ & $0,46 \%$ & 837 & 61 \\
\hline $\begin{array}{l}\text { Atividades de } \\
\text { Apoio } \\
\text { Agricultura e } \\
\text { Pecuária }\end{array}$ & $\begin{array}{c}\text { São Miguel } \\
\text { dos } \\
\text { Campos }\end{array}$ & 0,59 & 1,49 & $2,79 \%$ & $1,87 \%$ & 372 & 32 \\
\hline Laticínios & $\begin{array}{l}\text { Palmeira } \\
\text { dos Índios }\end{array}$ & 0,56 & 42,70 & $3,32 \%$ & $0,08 \%$ & 589 & 13 \\
\hline $\begin{array}{c}\text { Moagem, } \\
\text { Fabricação de } \\
\text { Prod. e } \\
\text { Alimentos } \\
\text { para Animais }\end{array}$ & Maceió & 0,50 & 2,23 & $6,09 \%$ & $2,74 \%$ & 1.468 & 11 \\
\hline $\begin{array}{l}\text { Fabricação de } \\
\text { Produtos de } \\
\text { Material } \\
\text { Plástico }\end{array}$ & Arapiraca & 0,53 & 6,66 & $3,09 \%$ & $0,46 \%$ & 1.069 & 11 \\
\hline $\begin{array}{c}\text { Fabricação de } \\
\text { Produtos de } \\
\text { Material } \\
\text { Plástico }\end{array}$ & Maceió & 0,53 & 1,94 & $5,29 \%$ & $2,74 \%$ & 1.831 & 51 \\
\hline $\begin{array}{l}\text { Manutenção e } \\
\text { Reparação de } \\
\text { Máq. e } \\
\text { Equipamentos }\end{array}$ & Maceió & 0,54 & 1,36 & $3,73 \%$ & $2,74 \%$ & 637 & 79 \\
\hline $\begin{array}{c}\text { Outros Tipos } \\
\text { de } \\
\text { Alojamento }\end{array}$ & $\begin{array}{l}\text { Litoral } \\
\text { Norte } \\
\text { Alagoano }\end{array}$ & 0,53 & 17,83 & $2,51 \%$ & $0,14 \%$ & 127 & 20 \\
\hline
\end{tabular}


Outros Tipos

Alojamento

Maceió

$0,53 \quad 1,98$

$5,43 \%$

$2,74 \%$

275

49

Fonte: Elaboração própria. MINISTÉRIO DO TRABALHO E EMPREGO. RAIS - MTE: Estabelecimento - ano base 2013. Disponível em http://bi.mte.gov.br/bgcaged/rais.php. Acesso em 10 de fevereiro de 2015.

São Miguel dos Campos é um entreposto comercial importante, com atividades industriais ligadas às Usinas de Açúcar e álcool, cimento e petróleo. Nessa localidade foi identificada a aglomeração em Atividades de Apoio à Agricultura e Pecuária. Em Maceió, quatro aglomerações foram identificadas, Moagem e Fabricação de rações para animais, Manutenção e Reparação de Máquinas e Equipamentos, Alojamentos (Turismo - Hotéis) e Plásticos. Podemos dizer que os aglomerados de Plástico de Maceió e Arapiraca possuem relação entre si, em virtude de pertencerem à mesma cadeia produtiva, dependente de um único grande fornecedor.

Os aglomerados de turismo localizados em Maceió e no litoral Norte são os únicos que correspondem parcialmente aos APLs que fazem parte do programa de apoio estadual PAPL. Assim, o destaque dessa pesquisa é a grande diferença entre o que foi identificado neste trabalho e os APLs que são foco do governo do estado com seu programa PAPL.

A despeito da correspondência entre os APLs identificados e os apoiados, não se pode afirmar que a política é inócua, ou que deveria ser abandonada por falta de representatividade dos setores na produção do Nordeste. O que tentamos demonstrar é que a política de APLs é mais adequada àquelas aglomerações que apresentam características fundamentadas na literatura, como a inovação, ação conjunta, importância econômica dentro da região, etc. As políticas direcionadas para aglomerados rudimentares, como os que encontramos em Alagoas, devem ser específicas e não horizontais como as de APLs. Deve ter o objetivo de promover a organização da produção, dando suporte a pequenos produtores de artigos de baixo valor agregado, como é o caso de muitos desses clusters, para que sejam capazes de comercializar seus produtos de maneira competitiva e constante, a fim de estabelecerem-se como produtores de um mercado mais exigente, aumentando a sua renda.

\section{6) CONCLUSÕES}

Identificar aglomerados industriais não é uma tarefa trivial e à prova de erros, ela deve ser acompanhada de critérios e métodos científicos e da 
observação da localidade e suas interconexões com o entorno através de pesquisa de campo. Da mesma forma, como descrito de forma exaustiva em toda a literatura de clusters e sistemas, não se pode criar um sistema produtivo local artificialmente, estes surgem espontaneamente a partir das características regionais, institucionais ou por alguma(s) característica(s) que diferencie a região das demais.

Os resultados do processo inicial de identificação de APLs na região Nordeste, especificamente para o estado de Alagoas, aqui colocado em evidência, indica uma quantidade muito menor de APLs identificados pelo método científico, do que aqueles que fazem parte do Programa estadual de APLs (PAPL), assim como uma ausência quase total de correspondência entre os APLs identificados pela pesquisa e aqueles apoiados no estado de Alagoas. Isso se deve ao fato de que grande parte dos APLs do programa não tem grande importância econômica em relação ao Nordeste, em termos do número de empregos nesses setores e número de estabelecimentos.

Alagoas é um dos menores estados da federação, tanto em território quanto na economia. Assim, como é de se esperar, poucos aglomerados produtivos importantes foram identificados. Todavia, isso não quer dizer que as políticas ligadas aos atuais APLs sejam desnecessárias ou equivocadas, são medidas que têm o objetivo de prover renda, emprego e evitar migrações, e desenvolver principalmente regiões mais pobres do estado. No entanto, essa plataforma de políticas públicas tão amplamente utilizada perde eficiência quando se misturam políticas de promoção de sistemas produtivos locais (ou APLs), que possuem características próprias de interação, inovação e redes, e políticas sociais de promoção de pequenos negócios em pequenos aglomerados de firmas rudimentares.

APLs com menor visibilidade se aproveitam dos recursos abundantes de programas federais e estaduais direcionados a promover os sistemas produtivos locais, mas não conseguem alcançar os mesmos resultados, e em muitos casos são considerados pelos próprios gestores desses programas como casos de insucesso. Todavia, o problema não está no aglomerado que não alcançou a maturidade econômica e os resultados esperados, mas sim na política que não está totalmente alinhada e adequada àquela situação, pois o aglomerado difere em muitos aspectos do que seria um sistema produtivo local ou APL, segundo a literatura. Em outros casos, o poder público, ao gerir programas e recursos, busca promover atividades unilateralmente em setores sem perspectivas de expansão, ou até "criar" APLs com objetivos políticos, desperdiçando recursos públicos em projetos sem qualquer perspectiva de 
desenvolvimento. As políticas para formas mais rudimentares de aglomerações devem estar pautadas na organização da produção, para que num momento posterior se possa pensar em inovação e competitividade.

As políticas públicas para aglomerados que não se encaixam dentro da descrição de sistemas produtivos locais devem ser diferenciadas, observandose a priori as características e especificidades locais, a fim de se estudar quais sejam as medidas e resultados esperados para cada ação. Algumas regiões não reagirão como se espera de um sistema (evoluindo, inovando, agindo em conjunto e ganhando mercado), mas podem ainda assim alcançar objetivos sociais e locais, desde que a política seja coerente. 


\section{REFERÊNCIAS}

AUDRETSCH, D. B.; FELDMAN, M. P. R \& D spillovers and the geography of innovation and production. American Economic Review 86 (3), 1996, p. 630-640.

CASSIOLATO, J. E.; LASTRES, H. M. M. Sistemas de Inovação: políticas e perspectivas. Parcerias Estratégicas, n. 8, 2000, p. 237-255.

COOKE, P.; MORGAN, K. The associational economy: Firms, regions and innovation. Oxford: Oxford University Press, 1998.

CROCCO, M. A. et al. Metodologia de Identificação de Arranjos Produtivos Locais Potenciais. Texto Para Discussão, n. 212 , Belo Horizonte: UFMG/ Cedeplar, 2003.

IPARDES. Instituto Paranaense de Desenvolvimento Econômico e Social e SEPL - Secretaria de Estado de Planejamento e Coordenação Geral, Governo do Estado do Paraná (2006). Arranjos Produtivos Locais do Estado do Paraná: identificação, caracterização e construção de tipologia. Curitiba: IPARDES.

KNORRINGA, P. Economics of collaboration: Indian shoemakers between market and hierarchy. Sage, New Dehli and London, 1996.

KRUGMAN, P. Geography and trade. Cambridge: MIT Press, 1991.

Development, geography and economic theory. Cambridge, MA: MIT Press, 1995.

KRUGMAN, P.; VENABLES, A. J. The Seamless World: a spatial model of international specialization. Discussion Paper, Centre for Economic Policy Research, London, n. 1.230, 1995.

LUSTOSA, M. C. et.al. Evolução e dinâmica da política de Arranjos Produtivos Locais em Alagoas. In: FAPEAL (Org.). Alagoas Contemporânea: Economia e Políticas Públicas em Perspectiva. Maceió: FAPEAL, 2014.

MAILLAT, D. From the Industrial District to the Analyses of Territorialized Productive Organizations. Working Paper, n. 9606b. Institut de Recherches Economiques et Regionales. Université de Neuchâtel, 1996.

MARKUSEN, A. sticky places in slippery space: a typology of industrial districts. Economic Geography, 1996, p. 293-313.

MARSHALL, A. Principles of economies: an introductory volume. New York: MacMillan, Eighth Edition, 1949, (Book IV).

NADVI, K.; SCHMITZ, H. Industrial Clusters in Less Developed Countries: review of experiences and research agenda. Discussion Paper, n.339, Institute of Development Studies, University of Sussex, Brighton, 1994. 
NORTH, D. C. Institutions, institutional change and economic performance. Cambridge University Press. United Kingdom, 1990.

PORTER, M.; The competitive advantage of nations. Macmillan, London, 1990.

Clusters and the new economics of competition. Harvard Business Review. NovDec, 1998, p. 77-90.

RABELOTTI, R. Recovery of a mexican cluster: devaluation bonanza or collective efficiency? World Development, 27 (9), 199, p. 1571-86.

SAXENIAN, A. Regional advantage: culture and competition in silicon valley and route 128. Cambridge, MA: Harvard University Press, 1994.

SCHMITZ, H. Collective efficiency and increasing returns. IDS Working Paper $\mathrm{n}^{\circ} 5$. Brighton: IDS/University of Sussex, 1997.

Global competition and local co-operation: success and failure in the Sinos Valley, Brazil, World Development, 27 (9), 1999, p. 1627-1650.

Clusters and Chains: how inter-firm organisation influences industrial upgrading. In: CASSIOLATO, J. E.; LASTRES, H. M. M.; MACIEL, M. L. (Eds.). Systems of innovation and Development: evidence from Brazil, Cheltenham, UK: Edward Elgar, 2003a, p. 273-290.

SUZIGAN, W.; FURTADO, J.; GARCIA, R.; SAMPAIO, S. Coeficientes de Gini locacionais (GL): aplicação à indústria de calçados do Estado de São Paulo. Nova Economia, v. 13, n. 2, jul.dez. 2003, p. 39-60.

Clusters ou Sistemas Locais de Produção: mapeamento, tipologia e sugestões de políticas. Revista de Economia Política, v. 24, n.4, out. dez. 2004, p.543-562.

SUZIGAN, W. (Org.). Identificação, Mapeamento e Caracterização Estrutural de Arranjos Produtivos Locais no Brasil. Relatório Consolidado. Brasília: IPEA, 2006. 